\title{
Determination of Vanadium Isotope Compositions in Carbonates Using a Fe Co-precipitation Method and MC- ICP-MS
}

\author{
LINHUI DONG ${ }^{1}$, WEI WEI ${ }^{1}$ AND FANG HUANG ${ }^{2}$ \\ ${ }^{1}$ University of Science and Technology of China \\ ${ }^{2}$ CAS Key Laboratory of Crust-Mantle Materials and \\ Environments, School of Earth and Space Sciences, University \\ of Science and Technology of China
}

Presenting Author: dlh0927@mail.ustc.edu.cn

Vanadium isotope compositions $\left(\delta^{51} \mathrm{~V}\right)$ in marine carbonates are a potential proxy to trace global redox states of ancient oceans. Although high-precision $\delta^{51} \mathrm{~V}$ analyses are available for lots of geological materials, carbonate-hosted $\delta^{51} \mathrm{~V}$ have not been reported yet due to extremely high matrix elements and low $\mathrm{V}$ contents (generally below $10 \mu \mathrm{g} \mathrm{g}^{-1}$ ). In this study, we developed a Fe co-precipitation method combined with a Fe column to preconcentrate $\mathrm{V}$ from major matrix elements, and following four-step chromatographic procedures to further purify $\mathrm{V}$ in carbonates. The $\delta^{51} \mathrm{~V}$ were measured using a sample-standard bracketing method by MC-ICP-MS. The robustness of this method was assessed by analyzing element-doping and matrixspiking synthetic carbonate solutions containing an in-house $\delta^{51} \mathrm{~V}$ standard, USTC-V. The mean $\delta^{51} \mathrm{~V}$ of the synthetic solutions $(0.06 \pm 0.08 \%$; $2 \mathrm{SD}, n=33)$ is in good agreement with the recommended value of the USTC-V $(0.07 \pm 0.08 \%$; $2 \mathrm{SD}$, $n=347$ ). The robustness was further validated by the consistent $\delta^{51} \mathrm{~V}$ of the igneous carbonatite standard, COQ-1, which were processed with the whole purification $(-0.48 \pm 0.04 \%$; $2 \mathrm{SD}, n=3)$ and only four-step chromatographic procedures $(-0.43 \pm 0.08 \%$; $2 \mathrm{SD}, n=3)$. For the first time, we obtained $\delta^{51} \mathrm{~V}$ of four carbonate reference materials: JDo- $1,-0.56 \pm 0.09 \%$ ( $2 \mathrm{SD}, n=27)$; JLs- 1 , $-0.61 \pm 0.14 \%$ o (2SD, $n=33$ ); GBW07217a, $-0.79 \pm 0.09 \%$ o (2SD, $n=6$ ); and GBW07214a, $-0.51 \pm 0.13 \%$ ( $2 \mathrm{SD}, n=48$ ). The longterm external precision of carbonate-hosted $\delta^{51} \mathrm{~V}$ analyses is better than $\pm 0.14 \%$ o (2SD). Our method can be applied to measure $\delta^{51} \mathrm{~V}$ in ancient carbonates to trace the evolution in global marine redox states throughout the Earth history. 